Military Technical College

Kobry El-Kobbah, Cairo, Egypt

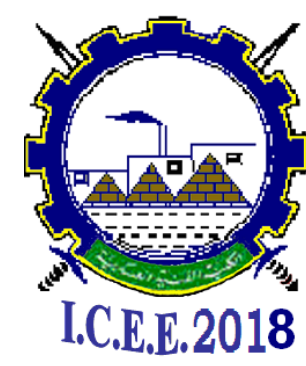

$9^{\text {th }}$ International Conference

on

Chemical \& Environmental

Engineering

3-5 April 2018

NRT-1

\title{
Advanced Technology and Safety Features of VVER-1200 Nuclear Power Plant
}

\author{
By
}

Prof. Dr. / Mohamed Kamal Shaat

\begin{abstract}
VVER-1200 (AES-2006) reactor is the latest evolution of VVER plant. It meets the advanced technology and the international safety requirements for G III+ nuclear power plants, which were consistent with IAEA International Nuclear Safety Group (INSAG) recommendations. The Russian general safety requirements are also consistent with the safety objectives specified by WENRA (Western European Nuclear Regulators Association) for new nuclear power plants.

The VVER-1200 is based on state of art design, which takes into account of Design Extension Conditions (DEC), in accordance with the current IAEA Safety Standards, and Fukushima lessons learned, as;

- The inherent safety: based on feedback control processes,

- Defense in depth: using successive barriers concept,

The main design concept for providing fundamental safety functions are:

- Passive systems: to deal with design extension conditions and beyond design basis accidents (BDBA), (e.g., passive SG cooling system, passive containment cooling system), and provide back- up for active safety systems.

- Multiple train redundancy: for control systems,

- Diversity: the back - up systems for providing the basic safety functions,

- Physical separation: all the four trains of safety systems and their control systems are physically separated. Also, the main control room and emergency control room are physically separated.
\end{abstract}

Prof. Nuclear Engineering, Reactors Department, Egyptian Atomic Energy Authority (EAEA) m_shaat3073@yahoo.com. Mobil 01224463983 